\title{
ESCAVANDO O CENTRO DE ESTUDOS CAMPANHENSE MONSENHOR LEFORT POLÍTICAS SANITÁRIAS PARA O CONTROLE DE DOENÇAS SEGUNDO JORNAIS DO INÍCIO DO SÉCULO XX
}

Lúcio Reis Filho

Anhembi Morumbi

RESUMO: 0 presente artigo visa divulgar pesquisa realizada no Centro de Estudos Monsenhor Lefort, localizado na cidade de Campanha, no sul do estado de Minas Gerais. As atividades consistiram na coleta de dados e análise das fontes primárias pertencentes ao acervo de impressos do Centro. Por meio de metodologia para a análise de textos em história, e considerando os documentos em sua historicidade, investigamos as políticas sanitaristas para 0 controle de doenças e a representaçãa destas nos jornais das primeiras décadas do século XX. Observamos, prioritariamente, o papel político da atividade jornalística naquele momento histórico, no que se refere à padronização do comportamento e à universalização de valores das classes dominantes.

PALAVRAS-CHAVE: História da imprensa. Sanitarismo. Profilaxia. Panaceia. Representação das doenças.

\section{DIGGING OUT THE MONSENHOR LEFORT STUDIES CENTER: SANITARY POLICIES FOR DISEASE CONTROL ACCORDING TO NEWSPAPERS FROM THE EARLY TWENTIETH CENTURY}

ABSTRACT: This paper aims to disclose the research held at the Centro de Estudos Monsenhor Lefort (Monseigneur Lefort Studies Center), an archive located in the city of Campanha, in the southern state of Minas Gerais. The activities carried out were data gathering and critical analysis of the sources belonging to the Centre's collection of press documents. Applying textual analysis and considering the documents in its historicity, we analyzed the sanitary policies for disease control, and the representation of diseases in newspapers from the first decades of the twentieth century. We observed primarily the political role of journalism in that historical moment and its intention to standardize the behavior through universalization of political and economic values of the dominant classes.

KEYWORDS: History of the press. Sanitarism. Prophylaxis. Panacea. Representation of diseases.

é historiador e doutorando do Programa de Pós-Graduação em Comunicação da Universidade Anhembi Morumbi | Laureate International Universities, São Paulo. 


\section{ESCAVANDO O CENTRO DE ESTUDOS CAMPANHENSE MONSENHOR LEFORT \\ POLÍTICAS SANITÁRIAS PARA O CONTROLE DE DOENÇAS SEGUNDO JORNAIS DO INÍCIO DO SÉCULO XX ${ }^{1}$}

Lúcio Reis Filho

INTRODUÇÃO

Apresentaremos nas próximas páginas os resultados da pesquisa de iniciação científica "Das Moléstias e dos Prodígios: profilaxia, panaceias e representação de doenças através de impressos na primeira metade do século XX". As atividades foram desenvolvidas no biênio 2013-2014, no Centro de Estudos Campanhense Monsenhor Lefort, com financiamento do Programa de Amparo à Pesquisa da Universidade do Estado de Minas Gerais (PAPq/UEMG). A pesquisa teve como objetivos: levantamento de notícias sobre o universo da saúde e das doenças, por meio de consulta à coleção de jornais sul-mineiros publicados dentro do recorte temporal proposto (primeira metade do século $X X$ ); elaboração de um banco de dados, alimentado pelas notícias encontradas; análise das notícias, a fim de observar a representação das doenças nesses jornais. Foram identificados e transcritos 493 artigos relacionados ao universo da saúde e das doenças, sendo 238 provenientes do A Campanha - semanário com o maior número de edições (836) disponíveis para consulta - e 255 dos outros 25 jornais sul-mineiros publicados nesse mesmo período.

As atividades de pesquisa foram realizadas a partir da "escavação" do acervo de impressos (especificamente os jornais) do Centro de Estudos Monsenhor Lefort. O Centro Monsenhor Lefort é uma seção especial da Biblioteca Pública Municipal Cônego Vítor - criada pela Lei Municipal n.1879/28-06-1996 —, de Campanha, Minas Gerais. Fundada em 1737, Campanha é considerada berço de diversos municípios da zona sul de Minas Gerais, tendo participado ativamente do cenário político, econômico e cultu-

\footnotetext{
${ }^{1}$ Agradecimentos à bolsista Graciley Vicentini Fernandes Borges e ao Programa de Amparo à Pesquisa da Universidade do Estado de Minas Gerais (PAPq/UEMG).
} 
ral do estado e do país. ${ }^{2}$ A cidade mantém ricos acervos documentais que remontam aos séculos XVIII, XIX e XX. Acervos como o do Centro Monsenhor Lefort, de valor inestimável para a pesquisa científica, têm possibilitado a interpretação e a reconstituição de amplo espectro da história regional, a partir de diversas abordagens.

A coleção particular do Monsenhor José do Patrocínio Lefort (19141997), doada ao Centro que recebeu o seu nome, mantém a "Seção de Documentos Históricos" para a preservação da memória da cidade e da região, composta por material impresso diversificado que compreende jornais, revistas, catálogos, livros cartoriais, livros de atas, editais e termos da Câmara Municipal. Para atender aos visitantes que buscam informações sobre Campanha, o Centro Monsenhor Lefort disponibiliza as obras completas de escritores campanhenses, bem como biografias de figuras que emprestam os seus nomes a ruas e logradouros públicos. Há, ainda, um conjunto bibliográfico sobre a história das cidades da região, como os raríssimos exemplares do Almanaque Sul Mineiro (1874-1884), de autoria do escritor campanhense Bernardo Saturnino da Veiga; parte de uma coleção de revistas produzidas pelo Arquivo Público Mineiro, abrangendo o período de 1896 a 1929; obras voltadas ao estudo de genealogia; esboços de árvores genealógicas, documentos e correspondências pessoais; medalhas, quadros e troféus.

Os volumes encadernados de jornais agregam exemplares avulsos e coleções completas de quase cem periódicos raros, alguns impressos em tipografia da cidade, no período de 1832 a 1966, e outros editados em cidades da região, como Elói Mendes, Lambari (antiga Águas Virtuosas), Varginha, Três Corações, São Gonçalo do Sapucaí, Campo Belo, Pouso Alegre, São Lourenço e Itajubá. De relevância inestimável para o campo da história social e cultural, ou mesmo para o estudo da história dos costumes e da imprensa no sul de Minas Gerais, essas fontes têm servido de apoio a historiadores e pesquisadores de grandes centros universitários do Brasil. ${ }^{3}$ No entanto, a municipalidade não tem assegurado ao Centro Monsenhor Lefort infraestrutura minimamente adequada para cumprir seus objetivos de guarda e preservação dos documen-

\footnotetext{
2 Enciclopédia dos Municípios Brasileiros, v. XXIV, 1958.

3 Dados de acordo com a entrevista concedida por Angélica Andrès, Diretora da Biblioteca Pública Municipal Cônego Vítor e coordenadora do Centro de Estudos Campanhense Monsenhor Lefort, a Adelino Ferreira, em 21 de maio de 2005.
} 
tos históricos, que permanecem armazenados de forma irregular. O Centro também não oferece condições adequadas para o uso científico.

\section{A HISTORICIDADE DOS IMPRESSOS}

De acordo com Douglas Kellner, há uma cultura veiculada pela mídia cujas imagens, sons e espetáculos ajudam a urdir o tecido da vida cotidiana, dominando o tempo de lazer, modelando opiniões políticas e comportamentos sociais, fornecendo o material com que as pessoas forjam sua identidade. A cultura da mídia foi primeiramente constituída pela imprensa, entre tantos outros produtos da indústria cultural. Organizou-se com base no modelo de produção de massa, segundo fórmulas, códigos e normas convencionais. ${ }^{4} \mathrm{O}$ impresso, portanto, consiste em material originário da indústria gráfica. Surgido com o advento da imprensa, encontrou no papel e nos similares seu suporte material. Ao longo dos séculos, os impressos tomaram grande diversidade de formas, que incluem livros, almanaques, circulares, jornais, revistas, pasquins, panfletos avulsos, boletins, cartazes, opúsculos, entre outros.

A imprensa nasceu com o capitalismo e acompanhou o seu desenvolvimento. Na realidade crescente de sua circulação, as publicações periódicas desempenharam papel ativo nos processos de transformações culturais, sociais e políticas que eclodiram na modernidade ocidental, a exemplo da secularização, urbanização e democratização de suas sociedades. Em outras palavras, "a história da imprensa é a própria história do desenvolvimento da sociedade capitalista." 5 Foi nesse passo, ritmado pelo desenvolvimento das relações capitalistas, que a empresa jornalística se estabeleceu no Brasil - apenas no século XX. Entretanto, Sodré questiona o estabelecimento da imprensa enquanto meio de massa neste país, uma vez que ela não seria de uso habitual de uma parcela numerosa e majoritária da população. ${ }^{6}$

Entender a imprensa em sua historicidade, sem perder de vista suas articulações mais amplas com a história do capitalismo, constitui o princípio norteador de nossa pesquisa. Observá-la através dessa lente, partilhada por Cruz e Peixoto, implica em tomá-la como força ativa da história do capita-

\footnotetext{
${ }^{4}$ KELLNER, Douglas. A cultura da mídia - estudos culturais: identidade e política entre $o$ moderno e o pós-moderno. Bauru: EDUSC, 2001, p. 9.

${ }^{5}$ SODRÉ, Nelson Werneck. História da Imprensa no Brasil. Rio de Janeiro: Mauad, 1999, p. 1.

${ }^{6}$ Ibidem, p. IX.
} 
lismo, problematizando suas articulações às conjunturas específicas do longo processo de constituição, construção, consolidação e reinvenção do poder burguês nas sociedades modernas, e às lutas por hegemonia nos diferentes momentos históricos do capitalismo. ${ }^{7}$

A Imprensa é linguagem constitutiva do social, detém uma historicidade e peculiaridades próprias, e requer ser trabalhada e compreendida como tal, desvendando, a cada momento, as relações imprensa/sociedade, e os movimentos de constituição e instituição do social que esta relação propõe. ${ }^{8}$

A historicidade inerente aos impressos abre vastas possibilidades de análise. Segundo Martins e Luca, "a história da imprensa é irmã siamesa da cidadania, do espaço público compartilhado e da democracia." Portanto, não há como escrever sobre a história da imprensa sem relacioná-la com a trajetória política, econômica e cultural das sociedades. Assim, parece-nos imprescindível observar a especificidade e a pluralidade das fontes; os atores que as escrevem e que mensagens transmitem; as estratégias, os apelos e os valores que esses veículos evocavam em seu discurso; suas condições de produção; o funcionamento das tipografias; de que forma esses textos chegavam ao público, considerando sua leitura e recepção. Percorrido esse caminho, Darnton destaca a importância de observar como os leitores entendiam os sinais na página impressa e quais eram os efeitos sociais dessa experiência. Ao propor uma história social e cultural da comunicação impressa, o autor indica que o estudo dos meios de comunicação em perspectiva histórica deve envolver todo o processo de sua construção, movimento que termina na interpretação dos leitores. ${ }^{10}$

Nosso trabalho fundamenta-se no pressuposto dito essencial das metodologias para a análise de textos em pesquisa histórica. Segundo Cardoso e Vainfas, a história é sempre texto, ou, mais amplamente, discurso, ou seja, o documento é sempre portador de um discurso que, assim considerado, não

7 CRUZ, Heloisa de Faria; PEIXOTO, Maria do Rosário. Na oficina do historiador: conversas sobre história e imprensa. Projeto História, n. 35, São Paulo, dez. 2007, p. 257.

8 Ibidem, p. 260.

9 MARTINS, Ana Luiza; LUCA, Tania Regina de (Org.). História da imprensa no Brasil. São Paulo: Contexto, 2008, p. 8.

10 DARNTON, Robert. O beijo de Lamourette: Mídia, Cultura e Revolução. São Paulo: Cia das Letras, 1990, p. 112. 
pode ser visto como algo transparente. ${ }^{11}$ Todavia, sublinhamos que a história não se reduz à estrutura do texto. Edward Muir expõe que as investigações históricas requerem uma apreciação cuidadosa das intenções e inclinações dos autores dos textos históricos. Aponta ainda que todos os eventos históricos podem ser entendidos apenas dentro do contexto de tempo e espaço em que ocorreram. ${ }^{12}$ Investigar o contexto sócio histórico no qual os impressos operam, pois, denota a importância de relacionar texto e contexto. ${ }^{13}$ Dessa maneira, pretendemos buscar os nexos entre as ideias contidas nos discursos, as formas pelas quais elas se exprimem e o conjunto de determinações extratextuais que presidem a produção, a circulação e o consumo dos mesmos, relacionando-os ao social.

Falar em história da imprensa é, portanto, se reportar ao que se produziu, de que forma, ao como se produziu, para quem se produziu e que consequências trouxe essa produção para a sociedade. É se referir, igualmente, à forma como o público reagiu àquelas mensagens e perceber de que forma realizaram leituras ou interpretações plurais. Formas de leituras, formas de apropriação, interpretações plurais de sentido. ${ }^{14}$

O mundo social é o ambiente em que os indivíduos e grupos elaboram suas práticas cotidianas, produzem representações e discursos sobre fenômenos históricos diversos, constroem sistemas de sentido que dão corpo a experiências singulares e coletivas. Portanto, o exame do material visual apoia-se na abordagem da nova história, cuja base filosófica reside na ideia de que a realidade é social ou culturalmente constituída. ${ }^{15} \mathrm{~A}$ história cultural, segundo Chartier, deve identificar o modo como dada realidade é construída,

11 CARDOSO, Ciro Flamarion; VAINFAS, Ronaldo. História e análise de textos. In: Domínios da história: ensaios de teoria e metodologia. Rio de Janeiro: Campus, 1997, p. 378.

12 MUIR, Edward. Ritual in early modern Europe. Cambridge: Cambridge University Press, 2005, p. 8.

13 Traduzida historicamente, a unidade de contexto diz respeito ao "contexto histórico", às estruturas sociais e/ou ao universo simbólico no qual se insere $(\mathrm{m}) \mathrm{o}(\mathrm{s})$ discurso(s) analisado(s). Unidade "arbitrária", posto que extratextual, que somente o historiador pode determinar, conforme suas opções teóricas, suas escolhas temáticas e suas hipóteses de investigação. CARDOSO, Ciro Flamarion; VAINFAS, Ronaldo. História e análise de textos, op. cit.

14 BARBOSA, Marialva. Como escrever a história da imprensa? II Encontro Nacional da Rede Alfredo de Carvalho, Florianópolis, abril 2004.

15 BURKE, Peter (Org.). A escrita da história: novas perspectivas. São Paulo: Editora UNESP, 1992. 
pensada e interpretada em diferentes contextos de tempo e espaço. ${ }^{16}$ Nesse sentido, falaremos em representações enquanto classificações que organizam a apreensão do mundo social como categorias de percepção do real. Burke complementa, ao sugerir que só acessamos o passado e o presente através de categorias e esquemas - ou, como diria Durkheim, às "representações coletivas" - de nossa própria cultura. ${ }^{17}$ Porém, "as representações são variáveis segundo as disposições dos grupos ou classes sociais; aspiram à universalidade, mas são sempre determinadas pelos interesses dos grupos que as forjam. $O$ poder e a dominação estão sempre presentes." ${ }^{" 18}$

Segundo Kellner, os impressos moldam a vida cotidiana e influenciam o modo como as pessoas pensam e se comportam, como se veem e veem os outros e como constroem sua própria identidade. ${ }^{19}$ Sodré percebe, ao constatar a influência que a difusão impressa exerce sobre o comportamento das massas e dos indivíduos, uma ligação dialética entre o desenvolvimento da imprensa e o desenvolvimento da sociedade capitalista. O traço ostensivo que parece comprovar tal ligação consistiria na tendência à unidade e à uniformidade, através da universalização de valores éticos e culturais, como pela padronização do comportamento. ${ }^{20}$

Cruz e Peixoto sublinham a impossibilidade de lidar com quaisquer fragmentos de um veículo da imprensa sem remetê-los ao jornal que os publicou numa determinada conjuntura. ${ }^{21}$ Ao observar o modo pelo qual determinada publicação se constitui como força histórica no interior de dada conjuntura espaço-temporal, Muir sugere o redirecionamento do objetivo da leitura e da análise para a configuração do projeto editorial, buscando desvendar sua historicidade e intencionalidade, uma vez que todos os documentos do passado foram escritos consoante certos propósitos, de acordo com as regras de composição textual vigentes em sua época. ${ }^{22}$ Dedicamo-nos a um corpus específico de textos e textualidades veiculado pelos jornais da zona sul de Mi-

${ }^{16}$ CHARTIER, Roger. A história cultural: entre práticas e representações. Lisboa: Difel, 1990.

17 BURKE, Peter. Variedades de história cultural. Rio de Janeiro: Civilização Brasileira, 2000, p. 72.

18 CARVALHO, Francismar Alex Lopes de. O conceito de representações coletivas segundo Roger Chartier. Diálogos, DHI/PPH/UEM, v. 9, n. 1, 2005, p. 143-165.

19 KELLNER, Douglas. A cultura da mídia - estudos culturais: identidade e política entre o moderno e o pós-moderno, op. cit., p. 10.

${ }^{20}$ SODRÉ, Nelson Werneck. História da Imprensa no Brasil, op. cit., p. 1-2.

${ }^{21}$ CRUZ, Heloisa de Faria; PEIXOTO, Maria do Rosário. Na oficina do historiador: conversas sobre história e imprensa, op. cit., p. 260.

22 MUIR, Edward. Ritual in early modern Europe, op. cit., 2005, p. 8. 
nas Gerais na primeira metade do século XX, bem como os modos de interseção entre os impressos e os movimentos políticos e sociais da época.

IMPRENSA, POLÍTICA E A UNIVERSALIZAÇÃO DOS VALORES DAS ELITES

Durante o ano de 2013, analisamos as 836 edições do semanário $A$ Campanha, que abrangem o período de 1900-1934. Este parece ter sido o periódico mais importante na região sul-mineira à época de sua publicação, e hoje é o que se apresenta em maior número nos volumes encadernados no acervo do Centro Monsenhor Lefort. A sua edição de estreia data de vinte e dois de setembro de $1900 .{ }^{23}$ "Leva na fronte, por título e por égide, o nome desta velha terra da Campanha [...]", município que outrora "falava por si e por todo o sul de Minas". A mensagem do editorial estabelece como objetivo servir a à sua terra. Quando saúda o reaparecimento do antigo Monitor SulMineiro, não o faz de forma acrítica. Ataca os seus redatores, por não "agitarem questões de controvérsia", e o próprio periódico, que se estaria limitando "a um simples noticiário e alguns artigos de moral e religião, não cogitando absolutamente de se fazer órgão de outras necessidades e aspirações da população campanhense". Diante disso, o autointitulado "órgão republicano do município" tais responsabilidades. "Na liça do jornalismo mineiro mais uma tenda se levanta", prossegue o editorial preocupado em discutir, "com imparcialidade e independência", todas as questões relativas aos interesses da cidade. Uma nota aparece no canto superior direito das primeiras edições:

\begin{abstract}
Aspirando a verdadeira ordem e o verdadeiro progresso e rezando o mesmo credo político que fez outrora as glórias do seu nome, $A$ Campanha é e será sempre a defensora convicta dos interesses deste município e a promotora estrênua de sua prosperidade.

Nessa atitude, A Campanha, trazendo em seu programa o pressentimento de seu futuro e a iluminar-lhe a rota a estrela brilhante de seu passado, se manterá franca, intransigente e enérgica - não esmorecerá nunca!
\end{abstract}

Dois pontos merecem destaque. Primeiro, Kellner entende a cultura da mídia como um terreno de disputa entre grupos sociais importantes e ideologias políticas rivais. Essa disputa seria vivenciada pelo público por meio dos

${ }^{23}$ CAMPANHA 1900 - SETEMBRO 20. A Campanha, Campanha, n.1, 22 set. 1900, p. 1-2. 
discursos veiculados pela mídia. ${ }^{24} \mathrm{Em}$ resumo, os jornais fizeram-se espaço privilegiado de luta simbólica, no qual diferentes segmentos digladiavam-se em prol de seus interesses e interpretações sobre o mundo. ${ }^{25}$ Segundo, Cohen considera jornalismo e literatura, imprensa e política equações desenvolvidas no ritmo das transformações sociais, e aponta para a formação de círculos dispostos a interferir nos destinos nacionais por meio da difusão de ideias. Uma radiografia da imprensa brasileira desde suas primeiras publicações evidencia as raízes políticas da atividade jornalística, que se teria constituído sempre a partir de determinados grupos sociais que viam na imprensa um meio de propagação de suas ideias e aspirações. ${ }^{26}$ Isso fazia rarear a variedade de tendências políticas.

No Brasil, a grande e a pequena imprensa remontam ao século XX. A grande imprensa, das capitais, fez do tema político a tônica de sua matéria. Tal e qual a pequena imprensa, das províncias, que no início do século não tinha estrutura de empresa e passava pela transição do artesanal para o industrial. Nas palavras de Sodré, "a matéria principal deles [dos jornais das províncias] é também a política, e a luta política assume, neles, aspectos pessoais terríveis, que desembocam, quase sempre, na injúria mais vulgar." ${ }^{27}$ A redação do A Campanha, órgão dito republicano do município, era composta por membros da elite sul-mineira, os "doutores" Ferreira Brandão, Brandão Filho, Braz Cesarino e Leonel Filho, sob a gerência de João Baptista de Mello. Seus anseios políticos transbordavam das páginas do impresso, que os tornava públicos, travestido com os princípios da imparcialidade e da justiça:

\footnotetext{
Um dos múltiplos e nobres misteres da boa imprensa é, sem dúvida, recolher a queixa justa que sobe da onda ululante dos que sofrem, para leva-la, como um protesto vigoroso, junto daqueles que, erguidos às alturas do poder, são infiéis às suas missões. [...] No jornal devem refletir-se as ondas sonoras da opinião pública, a fim de repeti-la indefinidamente no órgão auditivo dos governos. Fieis a esses princípios, abrimos de par em par nossas colunas que nunca desdenharam
}

\footnotetext{
${ }^{24}$ KELLNER, Douglas. A cultura da mídia - estudos culturais: identidade e política entre o moderno e o pós-moderno, op. cit., p. 10-11.

${ }^{25}$ LUCA, Tania Regina de. A grande imprensa na primeira metade do século XX. In: MARTINS, Ana Luiza; LUCA, Tania Regina de (Org.). História da imprensa no Brasil. São Paulo: Contexto, 2008, p. 158.

${ }^{26}$ COHEN, Ilka Stern. Diversificação e segmentação dos impressos. In: MARTINS, Ana Luiza; LUCA, Tania Regina de (Org.). História da imprensa no Brasil, op. cit., p. 104; 111.

27 SODRÉ, Nelson Werneck. História da Imprensa no Brasil, op. cit., p. 324.
} 
as causas justas, à toda e qualquer reclamação, sem nos importar o alvo que atinjam..$^{28}$

Os discursos veiculados pelo semanário permitem relacionar a história da imprensa com o papel político da atividade jornalística, que chegava ao público letrado à medida que o capitalismo avançava. Esse papel era comumente destacado pelo jornal, que nos tem permitido evidenciar o papel da imprensa "padronização do comportamento" 29 e na universalização de projetos, ideais e valores das elites.

\section{A PROFILAXIA (E A EXCLUSÃO) EM PROL DO ORDENAMENTO SOCIAL}

Para a corrente nacionalista da República Velha, que intentava superar o atraso e modernizar o país, um Brasil moderno significava necessariamente um Brasil europeizado. ${ }^{30}$ Nesse contexto, em que as classes dominantes buscavam implantar o ideal de civilização moderna derivado do modelo europeu, políticas de saúde pública igualmente modernas eram pensadas como fundamentais para a construção do Estado-Nação. ${ }^{31}$ A estas somam-se as medidas de embelezamento das cidades, originárias de uma preocupação com o efeito estético na disposição de conjuntos arquitetônicos. Higiene e estética tornam-se os objetivos principais que orientavam os melhoramentos da cidade no início do século. ${ }^{32} \mathrm{O}$ movimento sanitário, portanto, representou canal dos mais importantes para o projeto ideológico de construção da nacionalidade durante a República Velha, de modo que a ligação entre saúde pública e nacionalidade constitui traço marcante no movimento sanitarista. ${ }^{33}$

Em 1918, o médico e inspetor-sanitário Belisário Penna publicou Saneamento do Brasil. Nesta obra a questão sanitária toma um enfoque político.

28 NOTAS E NOTÍCIAS. A Campanha, Campanha, n. 668, 28 out. 1916, p. 1-2.

${ }^{29}$ SODRÉ, Nelson Werneck. História da Imprensa no Brasil, op. cit., p. 1-2.

30 SANTOS, Luiz Antônio de Castro. O pensamento sanitarista na Primeira República: uma ideologia de construção da nacionalidade. Dados: Revista de Ciências Sociais, Rio de Janeiro, v. 28, n. 2, 1985, p. 193-210.

${ }^{31}$ CAROLA, Carlos Renato. Estado civilizador e controle social de doenças (1930-1964). X Encontro Estadual de História - História: trabalho, cultura e poder. Florianópolis, ANPUH-SC, 2004, p. 104.

32 LEME, Maria Cristina da Silva. A formação do pensamento urbanístico em São Paulo no início do século XX. Espaço \& Debate: Revista de Estudos Regionais e Urbanos, São Paulo: Núcleo de Estudos Regionais e Urbanos, n. 34, p. 64, 1991.

33 SANTOS, Luiz Antônio de Castro. O pensamento sanitarista na Primeira República: uma ideologia de construção da nacionalidade, op. cit., 1985, p. 193-210. 
Penna conclui que, à exceção de São Paulo e em certa medida Minas Gerais e Rio Grande do Sul, os estados brasileiros só cuidavam das condições sanitárias das capitais e de algumas poucas cidades. Por essa razão, as populações rurais permaneciam no mais completo abandono. Várias eram as endemias em todo o país, com destaque para o amarelão, a malária e a doença de Chagas, às quais o governo central deveria combater através de uma política integrada de saneamento. Para lutar pela implementação de um programa de saúde pública em todo o país, Penna e outros sanitaristas fundaram a Liga Pró-Saneamento do Brasil em onze de fevereiro de $1918 .^{34}$ Liderada por Penna, a Liga pretendia alertar as elites políticas e intelectuais para a precariedade das condições sanitárias e obter apoio para uma ação pública efetiva de saneamento no interior. "Em um contexto no qual prosperava a ideia de salvação nacional, o sanitarismo encontrava-se sintonizado com as tendências gerais das correntes nacionalistas brasileiras [...]." ${ }^{35}$

A política sanitarista foi amplamente difundida na sociedade, o que pudemos atestar através da pesquisa com os jornais sul-mineiros. Em onze de maio de 1918, um artigo publicado pelo sul-mineiro Colombo veiculou dura crítica, de tom moralizante, contra as pessoas que faziam as necessidades fisiológicas na rua depois de uma noite de bebedeira. O jornal afirma que "a higiene pública se impõe como uma condição indispensável para o progresso de uma sociedade", e que "tal assunto é sobejamente conhecido por todos os que primam por ter um certo grau de educação." ${ }^{36}$ No período em que a matéria foi veiculada, a pequena burguesia urbana assumia função política proeminente. Conforme destaca Sodré, ${ }^{37}$ o público da imprensa pertencia majoritariamente a essa camada social, que influía nos jornais e era por eles influenciado. $O$ artigo do Colombo nos parece relevante, pois demonstra como os ideais do sanitarismo eram veiculados no interior do Brasil, nas primeiras décadas do século. ${ }^{38}$

Já no primeiro ano do século XX, a imprensa clamava por medidas de higienização que proíbam conservar chiqueiros dentro do perímetro urbano. $\mathrm{Na}$

\footnotetext{
34 Ibidem.

35 LIMA, Nísia Trindade; HOCHMAN, Gilberto. Pouca saúde, muita saúva, os males do Brasil são... Discurso médico sanitário e interpretação do país. Ciência \& Saúde Coletiva, Rio de Janeiro, v. 5, n. 2, 2000, p. 313-332.

${ }^{36}$ Colombo, Campanha, n. 37, maio 1918, p. 2.

37 SODRÉ, Nelson Werneck. História da Imprensa no Brasil, op. cit., p. 356.

38 PIEDADE FILHO, Lúcio F. R. Asseados e valorosos: o pelotão de saúde Oswaldo Cruz e sua cruzada higienista. In: Temporalidades, Belo Horizonte, v. 1, n. 2, ago./dez. 2009, p. 65.
} 
cidade sul-mineira de Águas Virtuosas, atual Lambari, "os suínos refocilados na lama empestam a atmosfera, desenvolvem o tifo, e entretêm nuvens de mosquitos." ${ }^{19} \mathrm{Em}$ vias de evitar "o acúmulo de focos miasmáticos, donde provem febres de mau caráter, e que exalam um fedido intolerável", o jornal $A$ Campanha aconselhou que, em matéria de higiene, é sempre mais prudente "antes prevenir do que curar". ${ }^{40} \mathrm{~A}$ discussão estava ainda viva sete anos mais tarde, quando o acúmulo de grande número de suínos, em pequenos pátios, era visto como infração flagrante à lei municipal e prejudicial à saúde pública. "A existência de chiqueiros nos pátios e terreiros da zona urbana nada mais é do que focos permanentes de miasmas pestilenciais." ${ }^{14} \mathrm{O}$ texto clamava pela promulgação de leis que proibissem esse tipo de estabelecimento.

A edição de nove de julho de 1912 do A Campanha denunciou focos de infecção em vários pontos urbanos, embora considerasse que os "germes do mal" poderiam ser facilmente removidos, e que isso dependeria do zelo de cada proprietário, a quem cabia cuidar da própria habitação. ${ }^{42}$ No sétimo mês de 1918, o jornal aplaudiu o serviço de saneamento rural de Minas, levado a cabo pelo governo do Estado por meio de decreto em que teria sido projetado um plano de profilaxia rural. De acordo com o semanário, os serviços de saneamento viriam a ser executados por meio de sérias medidas higiênicas, "combatendo-se, pelas obras de engenharia sanitária, as endemias e epidemias que, desgraçadamente, infestam este e outros estados". Com métodos "modernos e científicos", o governo de Minas visava, também, o combate à sífilis. ${ }^{43}$

A pesquisa também nos permitiu analisar o tratamento dado às doenças pela imprensa sul-mineira de início do século XX. Nos jornais $A$ Campanha e $O$ Campanhense localizamos uma antiga forma de representação do enfermo que o relaciona à feiura e à monstruosidade. Se, historicamente, "a doença carrega consigo a feiura", ${ }^{44}$ artigos publicados nesses jornais permitem confirmar essa tese. Descoberta particularmente instigante foi a imagem horrífica outrora atribuída aos hansenianos. Na sua História da feiúra (2007), Eco

\footnotetext{
39 PATEQUE, Garçon. A pedido. A Campanha, Campanha, n. 18, 26 jan. 1901.

${ }^{40}$ CHIQUEIROS. A Campanha, Campanha, n. 43, 27 out. 1901, p. 3-4.

${ }^{41}$ HIGIENE. A Campanha, Campanha, n. 379, 13 dez. 1908, p. 3-4.

42 PELA HIGIENE. A Campanha, Campanha, n. 499, 9 jul. 1912, p. 1.

43 SANEAMENTO DO ESTADO DE MINAS, O. A Campanha, Campanha, n. 718, 10 jul. 1918, p. 2.

${ }^{44}$ ECO, Umberto (Org.). História da feiura. Rio de Janeiro: Record, 2007, p. 256.
} 
transcreveu um excerto da Estética do feio (1853) de Karl Rosenkrantz, no qual se lê: "[...] a doença é causa do feio quando modifica de modo anormal a forma." ${ }^{45}$ Para Carlo Ginzburg, a repulsa responsável pela marginalização dos hansenianos na Idade Média colocava-os numa condição ambígua e limítrofe de "objetos de horror", porque a doença, "entendida como símbolo carnal do pecado", desfigurava os traços "quase dissolvendo sua aparência humana". ${ }^{46}$

Essa antiga forma de representação aparece em dois artigos do A Campanha. Na crônica natalina "O leproso", publicada em 4 de janeiro de 1902, CoeIho Neto evidencia o isolamento do enfermo: "Encolhido no lar, longe das gentes, canta. A pele roxa tressua, os olhos se encovam - é uma mandrágora viva. A lepra já vai lhe roendo os dedos, os lábios, as pálpebras, as orelhas, e ele, vendo-se aos poucos destruir, sofre calado ou geme solitário." Na edição de 19 de abril de 1903, ano em que foi publicada uma série de textos sobre a "Cura da Morfeia", o hanseniano é considerado "um infeliz fora da comunhão social", que vive "em companhia de seus irmãos de infortúnio [...] até que a morte, mais piedosa do que a sociedade, dá-lhe o seu beijo fatídico, e o pobre, que foi sempre um morto entre os vivos, encontra finalmente repouso e abrigo [...]". Leem-se também as seguintes considerações, que buscam justificar as políticas de exclusão:

\footnotetext{
O morfético, pelo estado especial de sua moléstia, além das úlceras que o mortificam, do aspecto medonho de suas chagas [...], é um exilado da sociedade que dele foge como de um foco epidêmico, já pelo pânico, já pelo asco que causa tão horripilante estado mórbido, e ficando isolado e quiçá entregue ao desprezo de seus concidadãos.
}

"Ainda sobre o problema da lepra", publicada em 17 de novembro de 1929, na edição n. 39 d’O Campanhense, reforça ainda mais a antiga representação dos hansenianos. A notícia afirma que "Há ainda entre leprosos [...] a velha e estupida lenda de que, para se curarem, devem transmitir a moléstia a sete pessoas." Em seguida, narra o que chamou de um "fato horripilante": durante os festejos do jubileu de Congonhas, em Minas Gerais, um romeiro, acompanhado de sua filha pequena, resolveu distribuir determinada

\footnotetext{
${ }^{45}$ ROSENKRATZ, Karl apud ibidem, p. 256.

${ }^{46}$ GINZBURG, Carlo. História noturna: decifrando o Sabá. São Paulo: Companhia das Letras, 1991, p. 50.
} 
quantia entre os "lázaros". Porém, antes de terminar a doação, um "morfético" de aparência jovem raptou a criança e saiu correndo em meio à multidão. Com o auxílio da polícia, o pai saiu no encalço da "repelente criatura", encontrada horas depois, quando, na ânsia de se ver curado, o "maldito" tentava "contaminar a infeliz menina, cujo corpo, pelas mordeduras do monstro, era uma chaga viva." Então, "A policia narrou [...] a antiga história das sete vítimas que cada um deles deve fazer para alcançar a cura. Aquela menina era a sua terceira vítima." A conclusão: "Não são raros os exemplos de morféticos que atacam e mordem pessoas sãs, de preferência as crianças, que, inermes, não lhes podem opor resistência à agressão assassina."

Nos excertos supracitados, observamos traços que relacionam o enfermo ao contágio e à impureza. De acordo com a antropóloga Mary Douglas, a reflexão sobre esta última é fruto do cuidado com a higiene e do respeito pelas convenções sociais. A impureza refere-se à relação entre a ordem e a desordem, o ser e o não ser, a forma e a ausência de forma, à vida e a morte; mas seria essencialmente a desordem, e esta, "ao mesmo tempo, símbolo de perigo e poder". 47 Portanto, consideramos que os impressos se apropriaram de metáforas, tropos e motivos alegóricos em vias de exercer papel fundamental na figuração das noções de profilaxia, promovendo tanto a exclusão dos enfermos como a veiculação de mecanismos de controle de moléstias em prol de uma sociedade ordenada e higiênica. Kellner complementa, ao sugerir que a cultura da mídia ajuda a modelar a visão prevalecente de mundo e os valores mais profundos, definindo o que é considerado bom ou mau, positivo ou negativo, moral ou imoral. ${ }^{48}$

Com o advento da imprensa sensacionalista na década de 1910, a saúde e as doenças tornaram-se alvo de interesse do público leitor. Nos jornais e revistas abundavam anúncios que ofereciam recursos milagrosos, panaceias como o Rum Creosotado, o Bromil, as Pílulas de vida do dr. Ross, o Fermento Lático Fontoura, que surgiam em um momento de desenvolvimento científico e tecnológico. Em relação à indústria farmacêutica, Ana Luiza Martins explica que o periodismo se tornou a última palavra em propaganda, e a repetição insistente

47 DOUGLAS, Mary. Pureza e perigo. Lisboa: Edições 70, 1991.

48 KELLNER, Douglas. A cultura da mídia - estudos culturais: identidade e política entre $o$ moderno e o pós-moderno, op. cit. 
acabava por induzir o leitor, quase automaticamente, a escolher e a adquirir o produto exaustivamente anunciado. ${ }^{49}$

$\mathrm{Na}$ edição de catorze de setembro de 1914 do A Campanha, a firma Daudt \& Lagunilla divulgou nota destinada "Aos consumidores de remédio"50 sobre seus quatro "preparados reconhecidamente eficazes", medicamentos considerados "infalíveis": A Saúde da Mulher, para curar incômodos de senhoras; o Bromil, para curar tosses, bronquite e coqueluche; o Bora Boracida, para feridas e todas as doenças da pele; e o Depurativo Lyra, para curar sífilis e eliminar as impurezas do sangue.

Os demais periódicos analisados também exploraram essa técnica. Neles, os remédios aparecem como "índice relevante da modernidade, um seguro contra as fraquezas e vulnerabilidades do corpo, um estímulo para a iniciativa e uma caução para o sucesso." ${ }^{51}$ Em sua época, Machado de Assis resumiu a equação: "O mundo caminha para a saúde e para a riqueza universais [...] assim se explicam os debates sobre medicina e economia e a fé crescente nos xaropes e seus derivativos." 52 No início do século XX, esses prodígios e curas milagrosas pareciam sinalizar os progressos da ciência, e também eram comumente noticiados pela imprensa estrangeira.

Nas capitais, conforme explica Nicolau Sevcenko, tal fenômeno decorre do intenso surto de urbanização, que trouxe para as cidades pessoas de origem rural, rompendo o contexto da família ampla e a cadeia de transmissão do conhecimento de ervas, tratamentos e processos tradicionais de cura. 0 lapso teria sido preenchido pelos novos laboratórios químicos e, sobretudo, pela rapidez dos oportunistas em se dar conta da nova situação. ${ }^{53}$ No interior, por outro lado, percebemos permanências dos chamados conhecimentos tradicionais. Em alguns casos, como no artigo intitulado "mordeduras de cobras", o jornal recorre à fé cristã para afirmar que "O remédio para a dentada de cobras impropriamente chamado 'pedra de cobra', não é mais que o chifre de cerco (veado) carbonizado." ${ }^{54}$ Em outros, os conhecimentos ditos tradicio-

49 MARTINS, Ana Luiza. Revistas em revista: imprensa e práticas culturais em tempos de República, São Paulo (1890-1922). São Paulo: EdUSP, 2001, p. 266.

50 Cf. CONSUMIDORES DE REMÉDIO, AOS. A Campanha, Campanha, n. 579, 14 set. 1914, p. 23.

51 SEVCENKO, Nicolau. A capital irradiante: técnica, ritmos e ritos do Rio. In: NOVAIS, Fernando A. (Coord.). História da vida privada no Brasil. São Paulo: Companhia das Letras, 1998.

${ }^{52}$ ASSIS, Machado de apud ibidem, p. 552.

53 Ibidem, p. 552.

${ }^{54}$ Cf. MORDEDURAS DE COBRAS. A Campanha, Campanha, n. 158, 10 jun. 1904, p. 3. 
nais parecem ter sido apropriados sob a égide da ciência. As experiências de dois químicos-farmacêuticos, os Irmãos Xavier e Torres, com o palmito amargoso, de uso comum entre os residentes do interior nas diferentes enfermidades do aparelho digestório, teriam resultado no Vinho de Paty Amargoso de Xavier, de uso recomendado em todas as moléstias do estômago, fígado e intestinos, como "má digestão, dores, azia, arrotos, enjoos, vômitos, dispepsias, gastralgia, etc. e na convalescença de todas as moléstias." 55

\section{CONSIDERAÇÕES FINAIS}

A reflexão crítica acerca do papel dos impressos nas diferentes esferas da vida social, política e cultural permite traçar conjecturas acerca da representação das doenças em práticas letradas sul-mineiras, no início do século XX. O posicionamento da imprensa em relação à moralidade ou à conduta social tem revelado feições políticas que operam em vias de articular e disseminar valores, sempre determinados pelas classes dominantes que almejavam manter o poder. Fosse nos grandes centros ou nas cidades do interior, como Campanha, eram os membros desses estratos que produziam os impressos, veículos solidificadores da força política das elites nas diferentes esferas da vida social. Determinantes no que se refere à formação da opinião pública, suas vozes podiam reclamar por medidas profiláticas, exigir a construção de mecanismos que evitassem a propagação de epidemias, ou mesmo propor que os enfermos fossem afastados da sociedade dos sãos, reforçando ideias pré-concebidas a respeito de determinadas doenças. No mundo moderno, que parecia caminhar rumo à saúde e à riqueza universais, as reluzentes possibilidades de consumo apareciam estampadas nos jornais. Impondo-se com toda a força, superavam métodos tradicionais de cura, introduziam padrões e conformavam o imaginário social. No entanto, vimos que nas Minas Gerais de início do século XX essas realidades eram construídas, pensadas e interpretadas de um modo particular, bastante distinto daquele dos grandes centros. Na zona sul-mineira, os triunfos da ciência ainda dividiam espaço com os velhos métodos, ainda muito presentes nas sociedades agrárias e tradicionais. Os dados levantados durante a pesquisa continuam sendo analisados, e ainda estamos longe de esgotar todas as possibilidades suscitadas pelas fontes documentais.

Recebido em: 26 de julho de 2016 Aceito em: 13 de setembro de 2016

55 Cf. PALMITO AMARGOSO NAS MOLÉSTIAS DO APARELHO DIGESTIVO, O. A Campanha, Campanha, n. 953, 28 nov. 1926, p. 3. 